\title{
TITLE:
}

\section{Does single stimulus elucidate the complex mystery of sleep?}

$\operatorname{AUTHOR}(\mathrm{S})$ :

Usami, Kiyohide

\section{CITATION:}

Usami, Kiyohide. Does single stimulus elucidate the complex mystery of sleep?. Clinical neurophysiology : official journal of the International Federation of Clinical

Neurophysiology 2020, 131(2): 463-464

ISSUE DATE:

2020-02

URL:

http://hdl.handle.net/2433/245430

\section{RIGHT:}

(c) 2019. This manuscript version is made available under the CC-BY-NC-ND 4.0 license

http://creativecommons.org/licenses/by-nc-nd/4.0/; The full-text file will be made open to the public on 01 Februan 2021 in accordance with publisher's 'Terms and Conditions for Self-Archiving'.; この論文は出版社版でありません。引 用の際には出版社版をご確認ご利用ください。; This is not the published version. Please cite only the published version. 


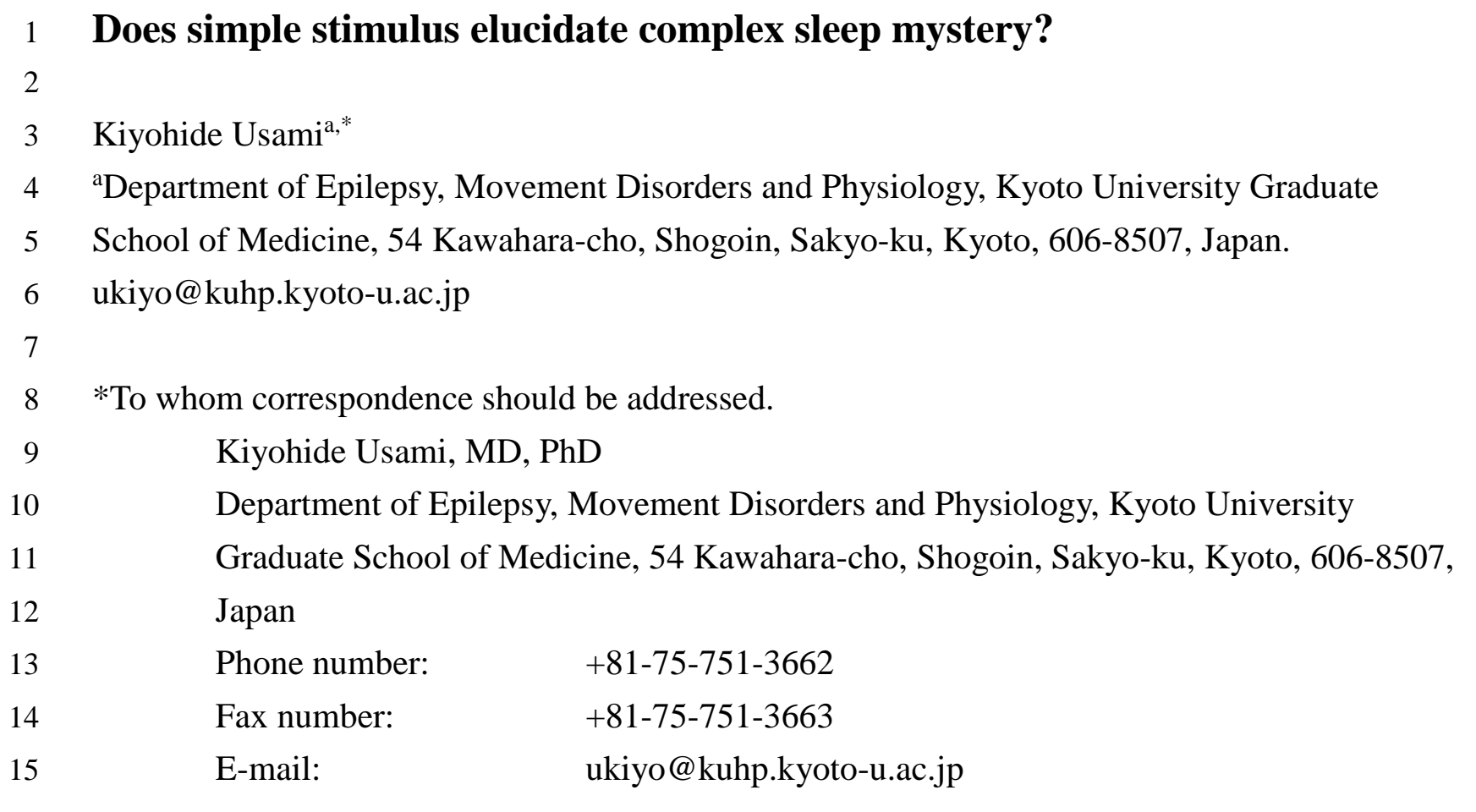

\section{Acknowledgement}

19 I thank Prof. Riki Matsumoto (the Department of Neurology, Kobe University, Japan) for his

20 insightful input. This work is supported by JSPS KAKENHI 19K21210 to KU.

\section{Conflict of Interest}

23 The Department of Epilepsy, Movement Disorders and Physiology, which KU belongs to, is an

24 Industry-Academia Collaboration Course supported by a grant from Eisai Company, NIHON

25 KOHDEN CORPORATION, Otsuka Pharmaceutical Co., and UCB Japan Co., Ltd. MK has

26 nothing to disclose.

27

28

29

30 
1 Every morning human beings awake from an unmindful world, sometimes having had peculiar

2 experiences or probably having changed minutely from their previous selves. Why do livings

3 beings on earth sleep? What is the specific aspect of sleep in human beings? The mystery of

4 sleep has continued to attract people since ancient times. Researchers in the field of neuroscience

5 are no exception. Sleep per se and sleep-associated issues such as unconsciousness, memory

6 consolidation, and sleep-related epilepsy, which have been investigated by means of various

7 contemporary cutting-edge techniques, have remained unsolved (Bazil, 2019, Boly et al., 2013,

8 Diekelmann and Born, 2010).

Since around 1990, and especially early in the 21 st century, single pulse electrical

10 stimulation (SPES) was introduced by researchers in multiple institutes across the world. SPES is

11 a simple technique to elicit responses at the cortices connected to the stimulus site possibly via

12 white matter (Matsumoto et al., 2017). Subsequently, we can analyze the induced responses

13 together with other variables such as the location of the response sites and areas with or without

14 epileptogenicity, to unveil brain connectivity (Entz et al., 2014, Lacruz et al., 2007, Matsumoto

15 et al., 2004, Wilson et al., 1990) and local epileptogenicity in the human cortex (Valentin et al.,

16 2005, Valentin et al., 2002, van 't Klooster et al., 2011), respectively. This unique perturbational

17 approach is limited to usage in patients who undergo invasive intracranial implantation. However,

18 it carries an advantage, in that, we can apply stimulation directly to the human cortex and look at 
1 the responses from the rest of the implanted channels with high spatiotemporal resolution no

2 matter what the patient's vigilance status is. Therefore, it was suitable to employ SPES for

3 investigating sleep (Pigorini et al., 2015, Usami et al., 2015) across various brain areas. In this line of research, to clarify the modulatory effect of sleep on cortical excitability,

5 the study by Arbune et al. recorded cortico-cortical evoked responses, i.e., cortico-cortical

6 evoked potentials (CCEPs) elicited by SPES during wakefulness and sleep stage N2, which are

7 characterized by spindles and k-complexes (Arbune et al., 2019) in 25 patients with implanted

8 stereo-EEG (SEEG). The authors focused on the amplitudes of the early components of the

9 CCEPs (10-100 ms after stimulation). Then, they applied a graph-theory approach to the

10 significant CCEPs to analyze the change in effective connectivity. They observed that sleep

11 globally increased CCEP amplitudes with some variance between local and distant connections,

12 and that frontal lobe connectivity was especially reinforced during sleep. The connectivity

13 between the hippocampus and temporal neocortex increased in the non-epileptogenic areas

14 during N2 sleep and some interhemispheric differences existed in the epileptogenic areas. CCEP

15 amplitude is the most classical index to be analyzed, and some of their results are also in

16 agreement with previous sleep studies (Pigorini et al., 2015, Usami et al., 2019, Usami et al.,

17 2015). In part, their results can be explained by sampling bias in SEEG, which was exclusively

18 done in clinical practice for patients. In this study, the electrodes of the left side were more 
1 included than the right, and the hippocampus was possibly well investigated. These factors might

2 have emphasized statistical significance of the specific connections. However, their large dataset

3 and meticulous methodology (Donos et al., 2016) that excludes false-positive connectivity make

4 their results robust so that we can expand on constructive discussions.

First, what do increased amplitudes during sleep indicate? Evoked response in general is

6 believed to reflect synchronization of neurons. However, we should consider that the amplitude

7 is calculated relative to the baseline. Thus, the plausible interpretation is that sleep absolutely

8 depresses the baseline - probably through some biochemistry - to apparently show CCEP

9 amplitude increase during sleep. To clarify the true effect of sleep on the degree of neuronal

10 synchronization, it may be needed to also analyze absolute values such as neuronal firing rates.

11 In addition, the degree of CCEP change caused by sleep seemed to be smaller in the

12 epileptogenic zone than in the non-epileptogenic zone in this study (the mean differences of

13 sleep-wake responses were $4.6 \mu \mathrm{V}$ vs. $5.7 \mu \mathrm{V}$ ), although large variability existed in the responses.

14 The seemingly counterintuitive result would be explained by the ceiling effect, which means that

15 CCEP is already large enough in the epileptogenic zone during wakefulness to attenuate the sleep

16 effect on CCEP augmentation. Second, from a clinical point of view, the predominance of sleep

17 modulatory effects on CCEPs at the frontal lobes would be vital to understand seizures of frontal

18 lobe epilepsy frequently occur during the non-rapid eye movement (REM) period (Herman et al., 
1 2001). Inherent nature of hypersynchrony in the frontal lobe may exist. Moreover, the

2 physiology of the protective effect on seizures or interictal discharges during REM (Bazil, 2019),

3 which were not analyzed in this article, and the characteristics of the other lobes (parietal,

4 temporal, and occipital lobe) in terms of excitability need to be further explored in the future.

5 Third, how the deep brain structure influences cortical network during sleep as well as the

6 generation of CCEP itself remain unsolved (Matsumoto et al., 2017). It is possible that we have

7 just scratched the surface by stimulating the cortex and focusing on the responses from the

8 superficial layer. One of the important structures would be the thalamus (Gent et al., 2018). How

9 could we reach the core that is a possible true conductor of the cortical symphony changed by

10 sleep? Combining CCEPs with non-invasive techniques such as functional MRI or diffusion

11 tractography imaging including deep brain structures could be an option.

12 We have been steadily accumulating data about sleep that deserve consideration as this

13 study by Arbune et al., though sleep is not yet completely understood. To untangle the

14 complicated mystery of sleep, we should think hard and maybe "sleep on it" (Hoffman and

15 McNaughton, 2002), hoping to re-organize our way of thought.

\section{References}

18 Arbune AA, Popa I, Mindruta I, Beniczky S, Donos C, Daneasa A, et al. Sleep modulates effective connectivity: a

19 study using intracranial stimulation and recording. Clinical Neurophysiology 2019. 
Bazil CW. Seizure modulation by sleep and sleep state. Brain Res 2019;1703:13-7.

2 Boly M, Seth AK, Wilke M, Ingmundson P, Baars B, Laureys S, et al. Consciousness in humans and non-human

3 animals: recent advances and future directions. Front Psychol 2013;4:625.

4 Diekelmann S, Born J. The memory function of sleep. Nat Rev Neurosci 2010;11(2):114-26.

5 Donos C, Maliia MD, Mindruta I, Popa I, Ene M, Balanescu B, et al. A connectomics approach combining structural and effective connectivity assessed by intracranial electrical stimulation. Neuroimage 2016;132:344-58.

Entz L, Toth E, Keller CJ, Bickel S, Groppe DM, Fabo D, et al. Evoked effective connectivity of the human neocortex. Hum Brain Mapp 2014;35(12):5736-53.

Gent TC, Bassetti C, Adamantidis AR. Sleep-wake control and the thalamus. Curr Opin Neurobiol 2018;52:188-97. Herman ST, Walczak TS, Bazil CW. Distribution of partial seizures during the sleep--wake cycle: differences by seizure onset site. Neurology 2001;56(11):1453-9.

12 Hoffman KL, McNaughton BL. Sleep on it: cortical reorganization after-the-fact. Trends Neurosci 2002;25(1):1-2.

13 Lacruz ME, Garcia Seoane JJ, Valentin A, Selway R, Alarcon G. Frontal and temporal functional connections of the 14 living human brain. Eur J Neurosci 2007;26(5):1357-70.

15 Matsumoto R, Kunieda T, Nair D. Single pulse electrical stimulation to probe functional and pathological

16 connectivity in epilepsy. Seizure 2017;44:27-36.

17 Matsumoto R, Nair DR, LaPresto E, Najm I, Bingaman W, Shibasaki H, et al. Functional connectivity in the human 18 language system: a cortico-cortical evoked potential study. Brain 2004;127(Pt 10):2316-30.

19 Pigorini A, Sarasso S, Proserpio P, Szymanski C, Arnulfo G, Casarotto S, et al. Bistability breaks-off deterministic 20 responses to intracortical stimulation during non-REM sleep. Neuroimage 2015;112:105-13.

21 Usami K, Korzeniewska A, Matsumoto R, Kobayashi K, Hitomi T, Matsuhashi M, et al. The neural tides of sleep

22 and consciousness revealed by single-pulse electrical brain stimulation. Sleep 2019.

23 Usami K, Matsumoto R, Kobayashi K, Hitomi T, Shimotake A, Kikuchi T, et al. Sleep modulates cortical

24 connectivity and excitability in humans: Direct evidence from neural activity induced by single-pulse electrical 25 stimulation. Hum Brain Mapp 2015;36(11):4714-29.

26 Valentin A, Alarcon G, Honavar M, Garcia Seoane JJ, Selway RP, Polkey CE, et al. Single pulse electrical 27 stimulation for identification of structural abnormalities and prediction of seizure outcome after epilepsy surgery: a 28 prospective study. Lancet Neurol 2005;4(11):718-26.

29 Valentin A, Anderson M, Alarcon G, Seoane JJG, Selway R, Binnie CD, et al. Responses to single pulse electrical 30 stimulation identify epileptogenesis in the human brain in vivo. Brain 2002;125:1709-18.

31 van 't Klooster MA, Zijlmans M, Leijten FS, Ferrier CH, van Putten MJ, Huiskamp GJ. Time-frequency analysis of 32 single pulse electrical stimulation to assist delineation of epileptogenic cortex. Brain 2011;134(Pt 10):2855-66.

33 Wilson CL, Isokawa M, Babb TL, Crandall PH. Functional connections in the human temporal lobe. I. Analysis of 34 limbic system pathways using neuronal responses evoked by electrical stimulation. Exp Brain Res 35 1990;82(2):279-92. 
